\title{
Undergraduate Research As A Fate Accompli: Innovation And Evolution Of A Student Conference In Business
}

Cheryl L. Buff, Siena College, USA

Raj Devasagayam, Siena College, USA

\begin{abstract}
The benefits of undergraduate research continue to receive academic attention and it is becoming an engaged learning practice present on many college campuses today. As research participation grows, an opportunity exists to showcase the work being accomplished and to use this public presentation to foster a culture of undergraduate research on campus, lobby for additional funding, and increase student and faculty participation. We describe the innovation and evolution of a student conference in business, sharing lessons learned and measureable results for the ten years this conference has been in place.
\end{abstract}

Keywords: Business Research; Engaged Learning; High-Impact Practices; Student Conferences; Undergraduate Research

\section{INTRODUCTION}

1 t has been suggested that showcasing undergraduate research as a fate accompli is the first step in garnering the respect and resources undergraduate research rightfully deserves (Buff \& Devasagayam, 2008). In other words, take the undergraduate research that is being performed on campus, highlight this research in a public forum, and use these opportunities as a means of securing additional resources, funding, and building institutional awareness and buy-in. In turn, these additional resources, funding, and attention should lead to an increase in the quantity and quality of undergraduate research and, therefore, more undergraduate research to showcase. As the cycle continues, a culture of undergraduate research on campus emerges and is fostered. An additional, synergistic approach to both initiating and showcasing on-going research is to point out the many favorable outcomes of undergraduate research (Bouldin, Hall, Oches, Szymanski \& Ledley, 2015; Craney, McKay, Mazzeo, Morris, Prigodich, and de Groot, 2011; Eagan, Sharkenss, Hurtado, Mosqueda \& Chang, 2011; Falconer \& Hollcomb, 2008; Lopatto, 2010; Moore \& Avant, 2008; Mathis, Datta, Ramos \& Gonzalez, 2015; Shanahan, Liu, Manak, Miller, Tan and $\mathrm{Yu}, 2015$; Szecsi, 2015), using them as a selling point for increased engagement in undergraduate research.

Approaching undergraduate research as a fate accompli is an interesting proposition to consider. Our experience suggests that using a student conference to promote and increase participation in undergraduate research is indeed effective and further, the conference visibly demonstrates the return on institutional investment around undergraduate research initiatives. The intent of this paper is to articulate how an undergraduate research conference in business has been used as a public forum for showcasing undergraduate research, thereby contributing to a growing culture of undergraduate research on campus. Further, it describes some of the innovations that have contributed to the evolution of the conference. Finally, measures of success are reviewed to demonstrate institutional return on investment.

\section{UNDERGRADUATE RESEARCH}

Undergraduate research is being embraced by institutions across the country (Carey, 2010), with undergraduates now engaged in academic initiatives that a generation ago would have been reserved for graduate students (Evans, 
2010). Institutions have adopted varying approaches to undergraduate research including infusing a pedagogy of research and discovery across the curriculum (Elrod, Husic, and Kinzie, 2010; Pukkila, Arnold Li \& Bickford, 2013; Szecsi, 2015) and in captstone courses (Hirsch, Lazarus, Wisler, Minde \& Cerasani, 2013; Lee \& Loton, 2015; see CUR Quarterly 2014 34(4) for entire issue dedicated to capstone experiences), forming undergraduate research learning communities (Kaul and Pratt, 2010), establishing undergraduate research programs abroad (Campbell \& Schnedier-Rebozo, 2014; Leek, 2014), developing summer student research programs (Craney et al. 2011; Falconer and Hocomb, 2008), using a framework to systematize the process by disicipline (Bartkus, Mills, \& Olsen, 2010; Moore \& Avant, 2008; Schiraldi \& Pedigo, 2015; Shanahan et al., 2015), and establishing institution-wide offices focused on communicating and increasing research endeavors by undergraduate students (Levenson, 2010). These initiatives are in part a response to thirty years of advocating the benefits of undergraduate research by the Council on Undergraduate Research (Elrod et al., 2010) and the realization that undergraduate research is a high-impact educational practice (Schiraldi \& Pedigo, 2015; Weight, 2010). Students actively engaged in learning have fuller, more relevant educational experiences (Falconer and Holcomb, 2008). Undergraduate research is also a key way for first-generation, low-income, and minority-group students to distinguish themselves academically and become desired candidates in a competitive environment (Shanahan et al., 2015). Additionally the institution benefits as undergraduate research can be used as an effective recruiting tool for high-performing students. Further, it is a good differentiation tool if peer institutions do not have a well-developed program and commitment to undergraduate research.

Undergraduate research benefits students interested in graduate school as well as those not planning postgraduate work, as critical thinking, problem-solving abilities, and analytical abilities are improved (Levenson, 2010; Moore and Avant, 2008). Specifically noted are, "knowledge-related gains such as intellectual curiosity and content knowledge; skill-related gains such as analytical and logical thinking, synthesis of interdisciplinary knowledge and skills in research processes; and professional advancements, such as influence on career plans and motivation" (Szecsi, 2015, p.42). Falconer and Holcomb (2008), exploring undergraduate research activities from the student perspective, report that the most important aspects of the research experience were personal relationships with faculty and other students and intellectual stimulation. Similarly, Craney et al. (2011) report that valued general outcomes of undergraduate research identified by students include "specific technical skills/job experience," "friendship/relationship," "resume," and "references." Students across disciplines also valued specific technical skills and professional development skills, preparing for graduate school, learning to do research and/or gaining knowledge in the area (Craney et al., 2011). Students that participate in undergraduate research have greater confidence it their ability, a deeper understanding of their major, better integration into academic and college life, and, not surprisingly given the aforementioned benefits, a greater likelihood of finishing college (Mathis et al., 2015) The benefits and value of undergraduate research are clear.

What follows is an overview of an undergraduate research conference in business at a liberal arts institution, a summary of lessons learned from ten previous conferences, and a reflection on the influence the conference has had on a developing culture of undergraduate research in both a School of Business and the institution. In providing this information, we hope to assist colleagues in establishing an undergraduate student research conference on their campus, which would then act as a stimulus and catalyst for undergraduate research opportunities and funding. Most faculty in undergraduate institutions are aware of the advantages associated with undergraduate research. However, the commitment to undergraduate business research is not as well established as the commitment noted in the natural sciences (Eagan Jr. et al., 2011; Weight, 2010). "Faculty mentored research in business schools (with some exceptions) is much rarer than it is in disciplines and colleges such as engineering or the sciences where a culture of undergraduate research is well established" (Mathis, et al. 2015, p.35). Further, the assessment of undergraduate research in the natural sciences occurs more frequently than research in the social sciences and humanities (Craney et. al, 2011). Therefore, it seems vital to highlight and bring recognition to research that is being conducted in business, social sciences, and the humanities. Funding for this important pedagogical tool is scarce and faculty often wonder how to communicate the importance of this activity to the larger academic community on their campus. This paper suggests that a research conference is among the most effective ways to showcase on-going undergraduate research and further stimulate participation in this important high impact learning practice. 


\section{UNDERGRADUATE RESEARCH CONFERENCE}

\section{Overview}

The authors teach at a private liberal arts college, with an AACSB accredited business school, and are the cofounders and co-chairs of the annual student conference in business. The conference was developed over ten years ago in response to AACSB accreditation, a mission of student-focused education, an increased number of substantive research projects being completed in the classroom, a growing number of primary research based independent studies, and an increased number of non-credit-bearing student-faculty research projects. A brief overview of the conference is provided below; however, for a full description of the design and development of the conference, please see Buff and Devasagayam (2008).

The conference is always scheduled for a Friday afternoon in April. The event begins promptly at 3:00pm with a one minute welcome from a conference co-chair. This is followed by a two-three minute welcome from the College President. The keynote address is next, lasting no more than 15 minutes, including questions and answers. By 3:30, students, faculty and conference attendees are heading to one of the concurrent sessions. By 4:30, students, faculty and attendees reassemble in the main meeting room for brief (approximately one minute each) presentations by student clubs officers (e.g., American Marketing Association, Accounting Students Association, and Financial Management Student Association). Then awards are presented for best papers and best presentations in each concurrent session. Additionally, the faculty mentor for the student earning a best paper award is acknowledged with a certificate and gift. Finally, a conference co-chair extends a vote of thanks and invites faculty and student presenters to a reception (held only if budget constraints permit). The conference ends promptly at 5:00pm. The primary motivation for keeping the conference moving along and no longer than two hours on a Friday afternoon is to ensure the continued participation of non-presenting students and faculty. Student attendance levels observed over the past ten years confirm the success of this approach. Offered below are some general recommendations and lessons learned from ten years of experience with the conference.

\section{Lessons Learned}

Start small: Begin with a limited number of concurrent sessions, using what is readily available to you in terms of student research and projects. Increase over time, but realize that the number of concurrent sessions will likely vary from year to year. Our results for concurrent sessions the past years note the growth from 2 concurrent sessions with less than 10 presentations in year 1 to a maximum of 5 concurrent sessions and over 23 presentations in year 7 , a quantitative measure of success.

Involve students in all aspects of the conference: Students run every aspect of the conference with the exception of manuscript review, manuscript selection, and best paper and best presentation awards determination. Select students who might have an interest in performing undergraduate research as well as those students whose interests lie in event planning, marketing, advertising, public relations, and copy writing. Identify students early in their academic careers and assign them roles with increasing responsibility each year. The advantages (e.g. student involvement and interest generation, experience with event planning, interest in engaging in research so that they can present at the conference, interaction with faculty outside of the classroom, skill development such as time management) significantly outweigh the disadvantage (e.g. since a new group of students is learning new roles and responsibilities each year, it is more time consuming to have students run this event than it would be if the faculty co-chairs did so). One of the lessons we have learned relates to co-chair responsibility. While our original goal was to have seniors serve as conference co-chairs and co-editors of conference proceedings, our experience suggests that a better pairing of co-chairs is one junior and one senior. This permits continuity at the conference chair and proceedings editor roles each year; junior co-chair in year 1 becomes senior co-chair in year 2 , and so on.

Involve your faculty colleagues: Clearly a number of faculty will be involved as mentors to students whose research is accepted for presentation. Additionally engage faculty colleagues to review papers, make best paper and best presentation decisions, and assist student track chairs in each concurrent session. Faculty colleagues will be important audience gatekeepers; look to faculty colleagues to announce the conference to their classes and advisees and to offer the event for extra credit. In order to facilitate the use of the conference for extra credit, we provide 
electronic templates of assignments to our colleagues that can be modified or used as is. Engaging faculty colleagues that do not serve as research mentors is critical to developing a culture of undergraduate research.

Work with what is readily available to you: "Celebrate and share what is already in place" (Healey, Jenkins, \& Lea, 2014, p.60). Conference tracks may vary from year to year based on the work that is being done by students and faculty colleagues. For example, during one academic year a significant number of problem based service learning projects were undertaken, thus the "Service Learning Session" was added. More recently, "Strategic Management Case Competition" was added as a session, recognizing the accomplishments of students in the capstone course. An additional example from the a recent conference was an "Advanced Cost Accounting Track" that included business plan proposals structured in response to a case and presented as a poster session. The most recent addition is an Entrepreneurship session. The top three business plans from the Entrepreneurship class are selected for presentation by the instructing faculty. They are evaluated by a panel of judges, using a rubric that is appropriate for both business plan evaluation and the presentation skills of the presenters. In some cases, the conference chairs took the initiative to suggest sessions, but it is heartening to note that on other occasions individual faculty mentors made session recommendations.

A second example of working with what is readily available to you involves the keynote speaker. Consider using career-accomplished alumni and friends of the college to avoid honorariums and minimize travel costs. The institutional advancement/development office is often a very willing and eager partner to grow friends of the college by inviting them to serve as keynote speakers. The synergies in this area cross the traditional faculty-administrator divide. Ensure however that the speaker will engage a student audience.

Communicate often and to different audiences using various communications tools: Communicate about the conference to multiple audiences and through multiple channels. Student co-chairs make announcements at School of Business faculty meetings beginning in early fall. Beginning in November, 'Call for Papers' announcements are displayed in academic buildings and faculty offices. The college newspaper prints event announcements about the upcoming conference, the call for papers, and as the conference date approaches, advertisements for the event itself. Articles are also written for the school newspaper pre- and post-conference. The Call for Papers is placed on the website, which is updated regularly to include electronic proceedings and pictures from previous conferences. Multiple electronic and in-person announcements are delivered to faculty, as are sample 'out of class exercises' should they choose to offer extra credit to students attending the conference. Multiple announcements and invitations are sent to students, including in-class announcements, email announcements, and Facebook invites. Additionally, we use TV monitors running continuous streaming of event announcements, tickers in our research labs, table tents placed in dining halls and student gathering spaces, and announcements in napkin containers in dining halls. Electronic invitations, and in some cases targeted phone invitations, are sent to representatives from Admissions, Alumni, and Development. For the past five conferences, Admissions has invited local accepted students to attend the conference. As part of their day, these students also attend a class in their anticipated major and enjoy a lunch with Admission's representatives and invited students.

Provide gifts and "takeaways: Most of the funds that are secured for the conference are used for this purpose. For a number of years we have used relatively inexpensive jotters and pens, printed with the conference name and logo, as gifts to conference attendees. They are placed on chairs along with a copy of the program. We have also used tote bags, branded with the conference name, as gifts in the past. Best paper and best presentation awards are engraved acrylics, with best paper awards provided in each topic area and best presentation awards provided for each track. Multiple copies of trade books are made available, free of charge, each year by a publisher representative. (In fact one year, in addition to numerous books, the rep gave away 4 remote controlled helicopters by writing "You've won a helicopter" in four copies of the gift book.) These books are used as gifts for each presenter, for the faculty mentors of best paper award winners, for faculty track chairs, faculty paper judges, and any individual (faculty, student, staff, and administration) that has helped with the conference in some way. Finally, participation certificates and a printed copy of the proceedings are given to each student presenter. It is vital to recognize each student presenter and their faculty mentor.

Lobby for funding: This can be challenging, especially when budgets are tight. While this conference has the support of the dean and administration, given the economic conditions over the past few years, that support has not 
resulted in complete funding. In instances where funding is tight, all monies made available to support the conference are directed to those items that will benefit students and, to a limited extent, the keynote speaker. This includes the best paper/presentation acrylic awards and participation certificates for presenting students, jotters and pens for conference attendees, and a thank you gift for the keynote speaker. Faculty stipends, a faculty-student reception, honorarium and travel expense reimbursement for the keynote speaker, are eliminated. (See Snow, DeCosmo, and Shokair (2010) for further examples of cost cutting measures for an annual undergraduate research symposium.)

Plan ahead: Schedule conference dates a year in advance, especially if there are space concerns on campus. Ensure that the event is placed on the college/university master calendar and that the college's communications office will be present to photograph the event. Secure the participation of key individuals (college/university president, vice president of Academic Affairs or Provost, dean, and keynote speaker) as early as possible.

\section{OUTCOMES}

Objective measures of success are focused on conference statistics as summarized in Table 1 below. The increase in undergraduate research in the School of Business cannot be solely attributed to the student conference, although faculty acknowledge that it has been a major contributor. Over the past ten years, the conference has grown and contracted as dictated by submissions and space availability. In the first seven years of the conference, we note a steady increase in the number of faculty mentors with students participating. More recently, we find a smaller number of faculty mentors overall. There is a core group of faculty who routinely have multiple students submitting and presenting papers at the conference. Student participation fluctuates, with more papers in the past two years being single author submissions. While we attempt to accommodate all worthy submissions, this is not always possible. In fact, given the goal to keep the conference limited to two hours with concurrent sessions, the size of the conference in year 7 may well represent the upper limit of the number of sessions, papers/presentations, and students that can be reasonably accommodated.

Table 1. Student conference in business

\begin{tabular}{c|c|c|c|c}
\hline SCSCB Conference & Sessions & Presentations / Papers & Student Authors & Faculty Mentors \\
\hline 2006 & 2 & 10 & 24 & 6 \\
\hline 2007 & 3 & 13 & 19 & 9 \\
\hline 2008 & 3 & 13 & 29 & 6 \\
\hline 2009 & 4 & 17 & 36 & 11 \\
\hline 2010 & 4 & 21 & 44 & 12 \\
\hline 2011 & 4 & 19 & 40 & $13^{*}$ \\
\hline 2012 & 5 & 23 & 46 & 15 \\
\hline 2013 & 4 & 22 & 40 & 10 \\
\hline 2014 & 4 & 15 & 32 & 10 \\
\hline 2015 & 4 & 20 & 28 & 10 \\
\hline
\end{tabular}

*strategy track -3 paper/presentations, no faculty mentors

However, quantitative results alone do not tell the entire story. Qualitative feedback from non-presenting students also suggests that the conference is having its intended impact of fostering a culture of undergraduate research, although some comments reveal that there is still a lack of awareness about faculty-student research opportunities. Students convey a level of surprise at the types of research projects their peers are engaged in and, at least a few, have sought out the opportunity to engage in mentored research after having attended the conference. Examples of student comments include: "I want to be able to do something like that."; "How did she get to do that?"; "He really presented in Chicago too?"

Other outcomes associated with increased emphasis on research in the School of Business include growing participation of faculty and students in our summer research programs and a small but increasing number of School of Business students traveling off-campus to present their research. We also note increases in the number of School of Business students participating in other on-campus presentation venues including discipline specific colloquia, the annual summer research symposium, and the annual academic celebration. Finally, our students are having their 
research published. The most recent would be a student that presented at the School of Business Conference in April and had his research published in the Huffington Post.

\section{DISCUSSION}

For undergraduate research to succeed at a liberal arts institution, a strong commitment by every aspect of the college community is required (Weight, 2010). A student conference visibly demonstrates commitment and institutional support for the faculty and students involved in undergraduate research. Further, the conference recognizes the efforts of faculty mentors, whose work with students through independent studies or non-credit bearing mentored research may otherwise go unnoticed. This is important as research suggests that "faculty who feel valued by their colleagues are more likely to take the extra step of working with undergraduates even if reward system and productivity disincentives exist" (Eagan Jr., et al, 2011, p.171). Non-monetary awards, such as faculty mentor awards, can play a crucial role in motivating junior faculty during times of economic austerity. Additionally, participation in the student conference is often mentioned with prominence in tenure and promotion applications as evidence of commitment to student engagement and learning.

Successful undergraduate research hinges on effective student-faculty mentoring relationships (Shanahan et al., 2015). It has been reported that undergraduate students may rely on faculty to establish the mentoring relationship (Eagan Jr. et al. 2011). Yet, interested students should feel they can approach faculty directly. Undergraduate research programs seemingly would benefit from tactics that facilitate the formation of a mentoring relationship (Schiraldi \& Pedigo, 2015; Shanahan et al., 2015). Certainly the visibility of faculty mentors at the student conference provides attending students with additional information on which faculty members are actively engaged in undergraduate research and may influence perceptions of approachability. This is consistent with the observations of Snow, DeCosmo, and Shokair (2010) who state that "a campuswide undergraduate research symposium can be an effective way to provide a forum for students to learn how to present their work, for undergraduates not yet involved in research to gain access to mentors and generate ideas for projects, for the university to showcase the powerful impact that research participation has on undergraduate education, and for students, faculty, and staff to discuss current research with community members and parents in a high-energy setting" (p. 18).

\section{CONCLUSION}

In closing, the dissemination of knowledge to one's peers is an invaluable part of critical thinking and learning that the student can then employ throughout their graduate programs and their professional careers. When asked if undergraduate research better prepared him for his professional endeavors, one student responded, "I definitely think that my research helped me prepare for a professional career. Not necessarily with the actual information I researched, because of the nature of my topic, but the entire process of researching, developing theories and a plan of action, and then following through with it while still managing a normal amount of class work." A student research conference provides the unique opportunity for students to experience the thrill of presenting their learning to the greater good of a learning community. For ten years, we have observed the success of the conference in bringing attention to undergraduate research occurring in the business school. The conference is growing and other initiatives to increase undergraduate research are emerging. In fact, the most recent strategic plan at our institution identifies high impact learning opportunities, including student-faculty collaborative research, as a key initiative. Funding for student travel is increasing. Funding for mentored research through independent studies is growing. Additionally, the Center for Undergraduate Research and Creative Activity was formed and provides additional research related programming, information and funding for our students. As the number of students engaged in high impact learning opportunities grows, we are very well prepared to showcase student success in the business school and to share our conference model with our faculty colleagues in the sciences and liberal arts, fostering a culture of undergraduate research that is institution-wide.

N.B. The authors are willing to provide all templates and documents associated with the Student Conference in Business to interested colleagues. 


\section{AUTHOR BIOGRAPHIES}

Cheryl Buff, Ph.D. is the Associate Dean of the School of Business at Siena College. She is the former Director of the Center of Undergraduate Research and Creative Activity. Dr. Buff received the Excellence in Teaching Award from Siena College in 2010. She has authored a number of articles in the areas of consumer behavior, branding, social media, sports marketing and pedagogy, with publications in leading journals such as Journal of Business Ethics, Sport Marketing Quarterly, Journal of Product and Brand Management, and Marketing Management Journal.

Raj Devasagayam, Ph.D. is the Chair of Marketing Department and Director of Center for Undergraduate Research and Creative Activity at Siena College, NY. He received Excellence in Teaching Award from Siena College in 2007

and Excellence in Teaching Award from St. Norbert College, Wisconsin, in 2003. His research in the areas of dispute resolution in customer/firm conflicts, channels, brand strategies, sports marketing, and marketing pedagogy, has been published in leading journals such as Marketing Management Journal, Journal of Brand Management, Journal of Product and Brand Management, Journal of Financial Services Marketing, Sport Marketing Quarterly, and Case Research Journal.

\section{REFERENCES}

Bartkus, Ken, Mills, Robert, \& Olsen, David. (2010). "Fostering Undergraduate Research Experiences in Management Information Systems Through the "Research Group" Framework." American Journal of Business Education. 3(6), 97 102.

Bouldin, Ryan M., Hall, Gregory J., Oches, Eric A., Szymanski, David W., \& Ledley, Fred D. (2015). "Connecting Business and STEM Education through Undergraduate Research.” CUR Quarterly, 35(4), 17-23.

Buff, Cheryl L. \& Devasagayam, Raj. (2008). "Developing an Undergraduate Research Conference in Business: A Model." Contemporary Issues in Education Research, 1(2), 37-41.

Campbell, Bill \& Schneider-Rebozo, Lissa. (2014). "Fifty Years of Undergraduate Research in Europe.” CUR Quarterly, 35(2), 7-13.

Carey, Shelley J. (2010). "From the Editor." Peer Review, 12(2), 3.

Craney, Chris, McKay, Tara, Mazzeo, April, Morris, Janet, Prigodich, Cheryl, \& de Groot, Robert. (2011). "Cross-Discipline Perceptions of the Undergraduate Research Experience." The Journal of Higher Education, 82(1), 92-113.

CUR Quarterly. (2014). “Undergraduate Capstone Experiences.” Council on Undergraduate Research, 34(4), Summer 2014.

Eagan Jr., Kevin M., Sharkness, Jessica, Hurtado, Sylvia, Mosequeda, Cynthia M., \& Chang, Mitchell J. (2011). "Engaging Undergraduate in Science Research: Not Just About Faculty Willingness.” Research in Higher Education, 52(2), 151157.

Evans, David R. (2010). “The Challenge of Undergraduate Research.” Peer Review, 12(2), 31.

Falconer, John \& Holcomb, Dianne. (2008). "Understanding Undergraduate Research Experiences form the Student Perspective: A Phenomenological Study of a Summer Student Research Program.” College Student Journal, 42(3), 869-878.

Healey, Mick, Jenkins, Alan \& Lea, John. (2015). Developing research-based curricula in collegd-based higher education. The Higher Education Academy: York, United Kingdom.

Hirsch, Susan F., Lazarus, Ned, Wisler, Andria, Minde, Julie, \& Cerasani, Gina. (2013). "Pursuing Research Through Focus Groups: A Capstone Experience Meets Disciplinary, General Education Goals." CUR Quarterly, 33(4), 23-27.

Kaul, Gitanjali, \& Pratt, Chaleyse. (2010). "Undergraduate Research Learning Communities for First-Year and Lower-Division Students.” Peer Review, 12(2), 20-21.

Lee, Nicolette \& Loton, Daniel. (2015). "Integrating Research and Professional Learning - Australian Capstones.” CUR Quarterly, 35(4), 28-34.

Leek, Danielle. (2014). "Developing U.S. Students' Skills in communication Research Through Ethnographies of Speech in Different London Settings." CUR Quarterly, 35(2), 14-19.

Levenson, Cathy W. (2010). "Enhancing Undergraduate Research in the Arts and the Humanities." Peer Review, 12(2), $13-15$.

Lopatto, David. (2010). "Undergraduate Research as a High-Impact Student Experience." Peer Review, 12 (2), 27-30.

Mathis, Carlton, Datta, Sumana, Ramos, Hector \& Gonzalez, Elsa Gonzalez y. (2015). "What Prevents Business Faculty and Latino Business Students from Participating in Undergraduate Research?” CUR Quarterly, 35(4), 35-41.

Moore, Linda S, \& Avant, Freddie. (2008). "Strengthening Undergraduate Social Work Research: Models and Strategies.” Social Work Research, 32(4), 231-235.

Pukkila, Patricia J., Arnold, Martha S., Li, Aijun Anna, \& Bickford, Donna M. (2013). "The Graduate Research concultant Program: Embedding Undergraduate Research Across the Curriculum.” CUR Quarterly, 33(4), 28-33.

Schiraldi, David A. \& Pedigo, Sheila. (2015). "Growth of an Engineering Department with Undergraduate Research." CUR Quarterly, 35(4), 24-27. 
Szecsi, Tunde. (2015). "Undergraduate Research in Humane Education: Benefits Gained in Action Research.” CUR Quarterly, $35(4), 42-46$.

Shanahan, Jenny O., Liu, Xiangrong, Manak, Jennifer, Miller, Suzanne M., Tan, Jing \& Yu, Chien Wen. (2015). "ResearchInformed Practice, Practice-Informed Research: The Integral Role of Undergraduate Research in Professional Disciplines." CUR Quarterly, 35(4), 6-16.

Snow, Allison A., DeCosmo, Janice, \& Shokair, Said M. (2010). "Low-Cost Strategies for Promoting Undergraduate Research at Research Universities.” Peer Review, 12(2), 16-19.

Weight, Greg. (2010). “The Integrity and Integrality of Student Research at a Liberal Arts College.” Peer Review, 12(2), 9-12. 